\title{
In-Situ Tensile-Creep Deformation Observations of a Cobalt-based Superalloy
}

\author{
S.C. Longanbach and C.J. Boehlert
}

Department of Chemical Engineering and Materials Science, Michigan State University, East Lansing, MI 48824

An in-situ tensile-creep testing methodology [1] has been applied to a cobalt-based superalloy, Udimet alloy 188, to investigate the effect of the grain boundary character distribution on the grain boundary cracking behavior. This methodology involves using an Ernest Fullam, Inc. (Clifton Park, NY) tensile stage to pull a sample at a constant load while heating the sample with a resistive heater. This experiment was performed in an XL-30 field emission gun scanning electron microscope at $760^{\circ} \mathrm{C}$. The temperature was monitored using two thermocouples spot welded to the edges of the sample which were not aligned for SEM imaging. The surface of the sample was imaged in-situ during the creep experiment without interrupting the test. The alloy was thermomechanically processed using a recipe that has previously shown a beneficial increase in creep resistance compared to other thermomechanical processing treatments [2]. In particular, the alloy sheet was subjected to three cold rolling passes of $35 \%$ deformation and a fourth pass of $10 \%$. After each cold rolling pass a heat treatment was performed at $1191^{\circ} \mathrm{C}$ for one hour. Based on previous observations [3] this heat treatment would provide full recrystallization of the worked microstructure.

Deformation in the form of cracking at the face centered cubic grain boundaries was observed using secondary electron imaging (see Fig. 1). Electron backscattered diffraction (EBSD) was performed on two different areas of the specimen surface both before the tensile-creep deformation and after 51 hours and approximately 18\% creep strain. An example of one such EBSD orientation map is provided in Fig. 2. The misorientations of 971 grain boundaries were characterized and classified as general high angle boundaries (HAB), low angle boundaries (LAB), or coincident site lattice boundaries (CSLB). The deformation observations of this sample reflected one main result; $73 \%$ of all the grain boundaries that had cracked during the creep deformation were HAB. Thus as has been determined in previous studies [1], where less numerous grain boundaries were analyzed, HAB were the most susceptible to grain boundary cracking. These results provide firm evidence that the LAB and CSLB in this alloy are more resilient to cracking during creep. It is noted that after the thermomechanical processing treatments, the grain boundary character distribution was the following: $0.75 \mathrm{CSLB}, 0.22 \mathrm{HAB}$ and $0.03 \mathrm{LAB}$. Twin boundaries accounted for $83 \%$ of the CSLB and $62 \%$ of the total boundaries in the sample. The thermomechanical processing treatments used in previous works indicate it is difficult to impose combined CSLB and LAB fractions larger than 0.78 in this alloy. Thus this puts practical limitations on obtaining lower fractions of HAB in the microstructure and in turn limits the effect of grain boundary engineering on the creep resistance of superalloys.

\section{$\underline{\text { References }}$}

[1] C.J. Boehlert et al., Philosophical Magazine., Vol. 88 Issue 5 (2008) 641-664.

[2] S.C. Longanbach and C.J. Boehlert, Proceedings of Superalloys $2008\left(11^{\text {th }}\right.$ International Symposium on Superalloys), (TMS, Warrendale, PA) eds. Roger C. Reed et al. (2008) 461-468.

[3] R.B. Herchenroeder et al., Cobalt, 54 (1972), 3-13. 

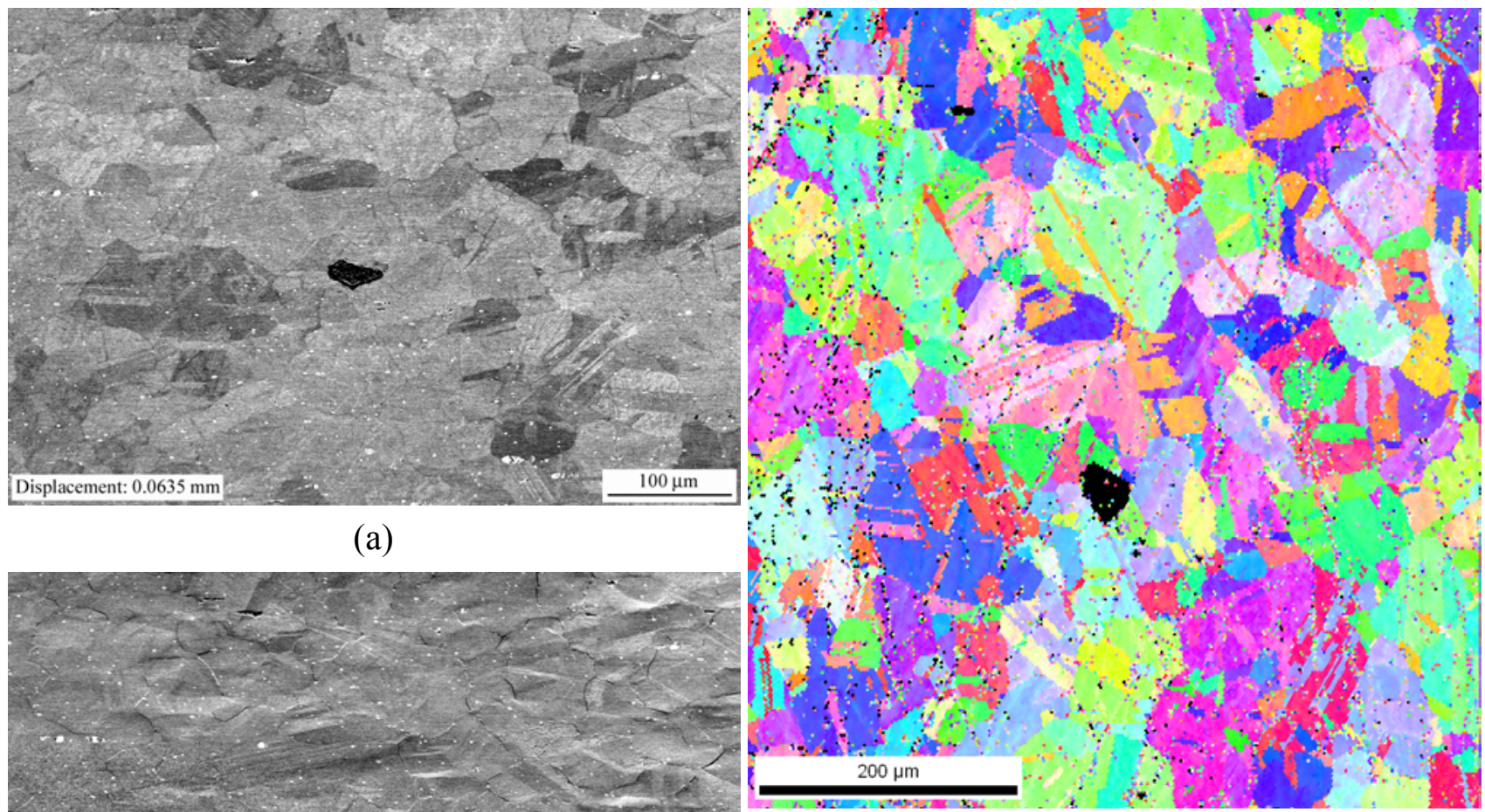

(a)

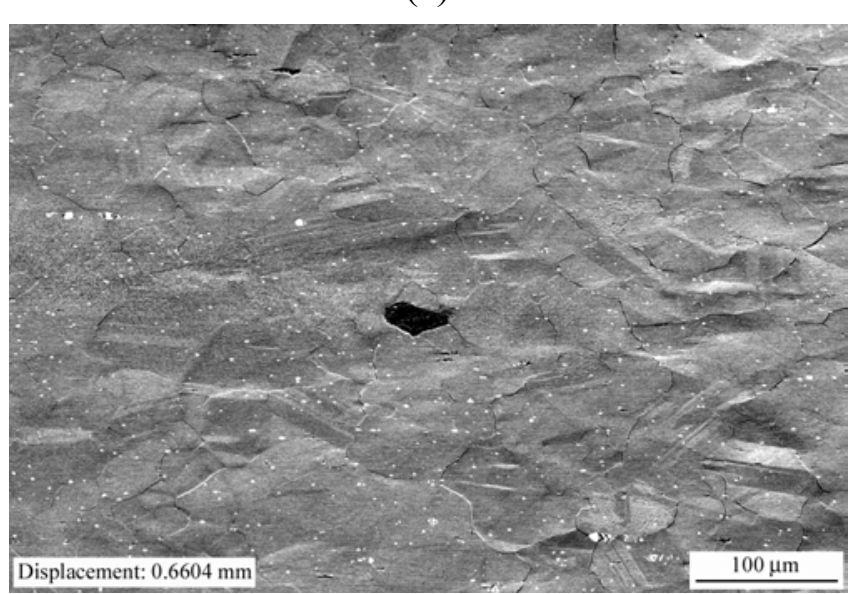

(b)

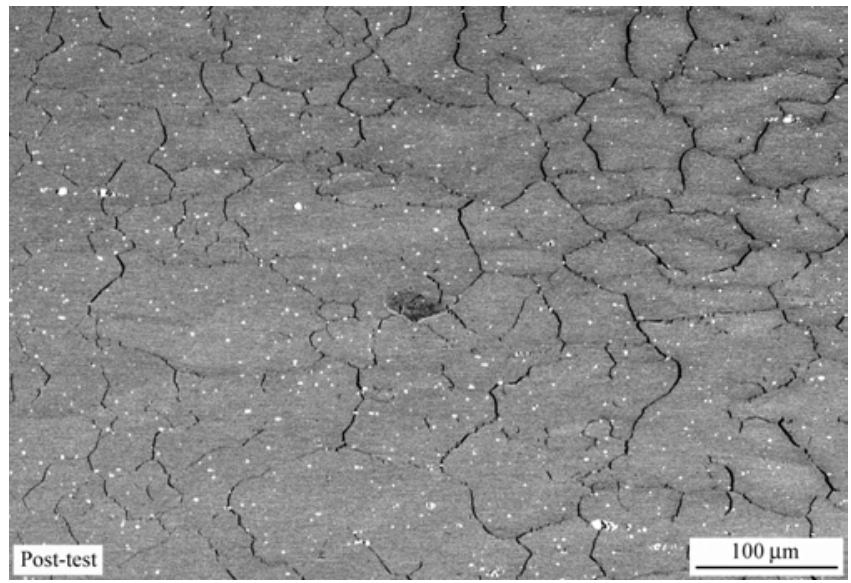

(c)

FIG. 1.Secondary electron SEM photomicrographs of the same area of the surface of the specimen after creep displacements of (a) $0.0635 \mathrm{~mm} \mathrm{(} 0 \%$ creep strain), (b) $0.6604 \mathrm{~mm}(\sim 10 \%$ creep strain $)$ and (c) $>1.123 \mathrm{~mm}(\sim 18 \%$ creep strain). The creep conditions were $\mathrm{T}=760^{\circ} \mathrm{C}$ and $\sigma=220 \mathrm{MPa}$.

(a)

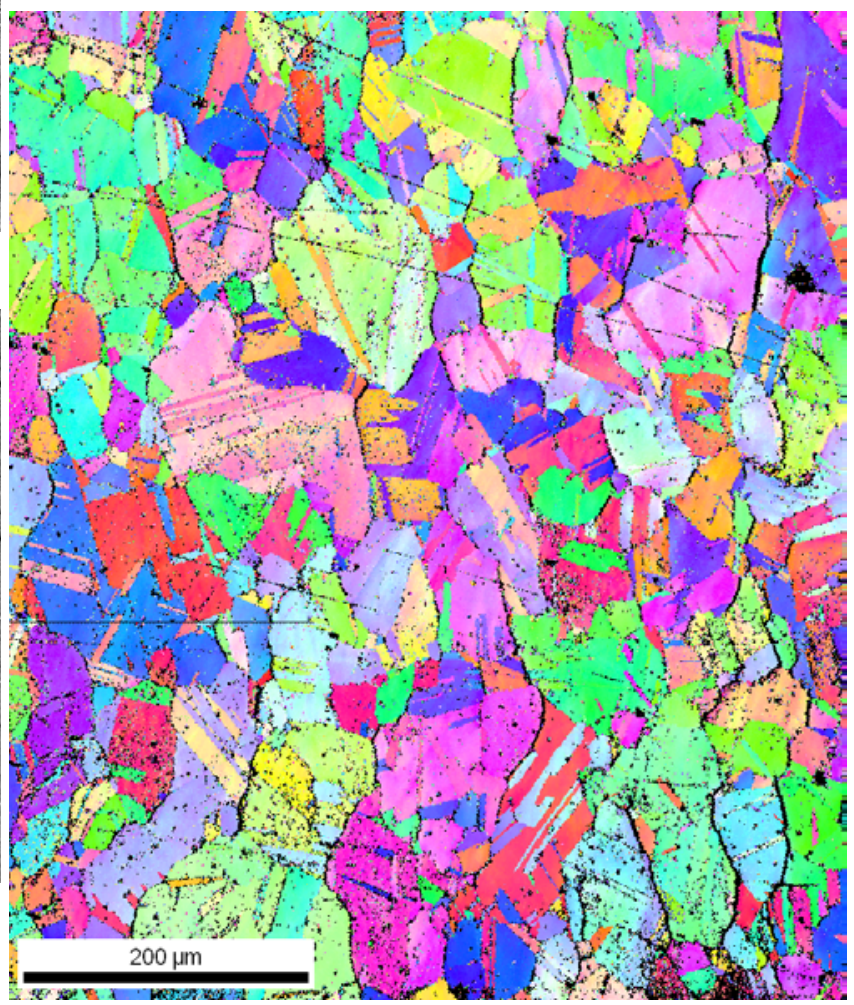

(b)

FIG. 2. EBSD orientation maps of the same area of the specimen imaged in Figure 1 (a) before creep and (b) after $\sim 18 \%$ creep strain. 